\title{
The I-neb Adaptive Aerosol Delivery System Enhances Delivery of $\alpha 1$-Antitrypsin with Controlled Inhalation
}

\author{
David E. Geller, M.D. and Kenneth C. Kesser, R.R.T.
}

\begin{abstract}
Background: Inhaled $\alpha 1$-antitrypsin (AAT) is being developed for treatment of cystic fibrosis to protect the lungs from excessive free elastase. High drug costs mandate a very efficient aerosol system to deliver a high payload to the airways. The I-neb Adaptive Aerosol Delivery (AAD) System is a portable, electronic, vibrating mesh nebulizer that delivers aerosol only during inhalation. It can be operated in conventional tidal breathing mode (TBM) or in target inhalation mode (TIM) that guides the patient to inhale deeply and slowly. The purposes of this in vitro study were to determine aerosol characteristics, device efficiency, and delivery time of AAT using the I-neb AAD System with TBM and TIM.

Methods: We studied the I-neb AAD System in TBM and TIM (inspiratory time 6 or $9 \mathrm{sec}$ ) using a breath simulator. The loaded dose was $0.5 \mathrm{~mL}$ AAT $(50 \mathrm{mg} / \mathrm{mL})$. Nebulized drug captured on an inspiratory filter was reported as emitted dose. Particle size was measured by laser diffraction. Predicted lung doses were calculated based on the results of a prior scintigraphy study of the I-neb AAD System.

Results: Particle size (VMD) for TBM and TIM was similar $(4.4-4.8 \mu \mathrm{m})$. The emitted doses were very high and similar between modes (82-90\% of loaded dose). Predicted lung dose of AAT (percent of loaded dose) and delivery times were: TBM 56.6\% in $7.5 \mathrm{~min}$; TIM-6 59.9\% in $4.4 \mathrm{~min}$; and TIM-9 64.5\% in $2.5 \mathrm{~min}$.

Conclusions: The I-neb AAD System enhanced AAT delivery by inhalation-only aerosol generation and a lowresidual dose. Predicted lung dose was high for both TBM and TIM, but longer inspiratory times with TIM reduced the administration time to one-third that of tidal breathing. We conclude that slow, deep, controlled inspirations using the I-neb AAD System is an efficient method to deliver AAT.
\end{abstract}

Key words: $\alpha 1$-antitrypsin, cystic fibrosis, aerosol devices, breath control, I-neb AAD System

\section{Introduction}

C HRONIC AND PROGRESSIVE LUNG DISEASE is the cause of the majority of morbidity and mortality in people with cystic fibrosis (CF). The lung disease is characterized by chronic endobronchial infection and an exaggerated inflammatory response, recruitment of large numbers of activated neutrophils, and release of elastase and other inflammatory mediators into the airway milieu. ${ }^{(1)}$ Elastase is a serine protease that helps bacterial killing, but when levels are elevated as in $\mathrm{CF}$, the neutralizing effects of endogenous antiproteases are overwhelmed. Griese et al. ${ }^{(2)}$ recently reviewed the many pathophysiologic consequences of a protease-antiprotease imbalance in CF, including degradation of lung matrix components (elastin, collagen, fibronectin, and other proteins), damage to cilia, inactivation of other antiproteases, cleaving of complement receptors and immunoglobulin G, degradation of surfactant proteins $\mathrm{A}$ and $\mathrm{D}$, stimulation of mucus secretion, and increased release of inflammatory mediators like IL- 8 and leukotriene $B_{4}$. The resulting structural damage to the airways, impaired mucociliary clearance, and crippled pulmonary host defenses lead to a downward spiral of infection, inflammation, airway obstruction, and bronchiectasis. ${ }^{(1)}$

$\alpha 1$-Antitrypsin (AAT) is a glycoprotein that irreversibly inactivates elastase, and is released by the liver, alveolar macrophages, and neutrophils. Patients with hereditary deficiencies of AAT are treated with commercially available intravenous (i.v.) formulations of AAT (Prolastin ${ }^{\circledR}$, Talecris, Research Triangle Park, NC, USA; Aralast $\mathrm{NP}^{\circledR}$, Baxter Healthcare, Westlake Village, CA, USA; Zemaira ${ }^{\circledR}$, CSL Behring, Kankakee, IL, USA), all produced from pooled 
human plasma, a very limited resource. ${ }^{(2)}$ Only $2 \%$ of the i.v. dose reaches the lungs, ${ }^{(3)}$ and because CF patients may have very high levels of free elastase in the airways, the dose of i.v. AAT required in $\mathrm{CF}$ is prohibitive. Therefore, aerosolized AAT is an attractive option in CF to target the disease site and achieve high airway concentrations of AAT that can mitigate the damaging effects of elastase. In the 1990s, small studies using jet nebulizers to aerosolize AAT showed that if enough drug reached the airways, the free elastase in bronchoalveolar lavage (BAL) fluid could be completely blocked. ${ }^{(4,5)}$ However, to achieve adequate local AAT concentrations, it was necessary to deposit tens of milligrams of AAT in the lungs. ${ }^{(2)}$ The conventional jet nebulizers used in these early studies are relatively inefficient, waste large amounts of drug, and are time-consuming, so are not ideal for costly drugs like AAT that are in short supply.

To optimize the aerosol delivery of AAT, it is necessary to maximize the delivery efficiency of the delivery system and reduce the intra- and intersubject dose variability to achieve a consistent, high-payload dose to the lungs. Also, CF patients are burdened with several other inhaled therapies on a daily basis, so the delivery time should be short and convenient. ${ }^{(6)}$

Deposition of aerosol drugs in CF airways can be improved by controlling the breathing pattern of the patient. Brand et al. ${ }^{(7)}$ showed that total respiratory tract deposition varied widely for spontaneous breathing patterns in subjects with obstructed airways. The variability was reduced and deposition increased when inhalation was controlled, using large tidal volumes and slow inhalation rates. The severity of disease did not affect total lung deposition. ${ }^{(7)}$ In a study of CF subjects, the same investigators found that peripheral deposition was highest when $2-3-\mu \mathrm{m}$ particles were inhaled with large inspired volumes and flow rates of 250-500 $\mathrm{mL} / \mathrm{sec}^{(8)}$ Bronchial deposition was maximized with particles in the 5-6- $\mu \mathrm{m}$ range using lower inspired volumes and lower inspiratory rates. ${ }^{(8)}$ Thus, high efficiency and reproducibility of aerosol delivery may be achieved by using an aerosol device that controls inhaled volume and rate.

The I-neb AAD System (Philips Respironics, Parsippany, $\mathrm{NJ}$ ) is a third-generation Adaptive Aerosol Delivery (AAD) system that combines vibrating mesh aerosol generation, dosimetric drug delivery (metering chamber), and the AAD Disc technology for operational parameters (Fig. 1). AAD systems employ electronic means to adapt the timing of aerosol delivery to the patient's breathing pattern and to improve the precision and reproducibility of dosing. The microchip AAD Disc determines the power supplied to the vibrating mesh that governs aerosol output, and can be customized. The dose-metering chamber has a low-residual volume and comes in various sizes to accommodate the dose requirements of different drug formulations. ${ }^{(9)}$

The I-neb AAD System can be operated in two different breathing patterns, the Tidal Breathing Mode (TBM) and the Target Inhalation Mode (TIM). In TBM breathing, the device continually monitors the patient's breathing pattern, adapts to any changes based on a rolling average of the prior three breaths, and then releases aerosol during the first 50 to $80 \%$ of inspiration (minimizing the amount of drug wasted during exhalation). With this mode there is no control over how fast a patient inhales. However, with TIM, the mouthpiece restricts inspiratory flow to less than $20 \mathrm{Lpm}$ (about

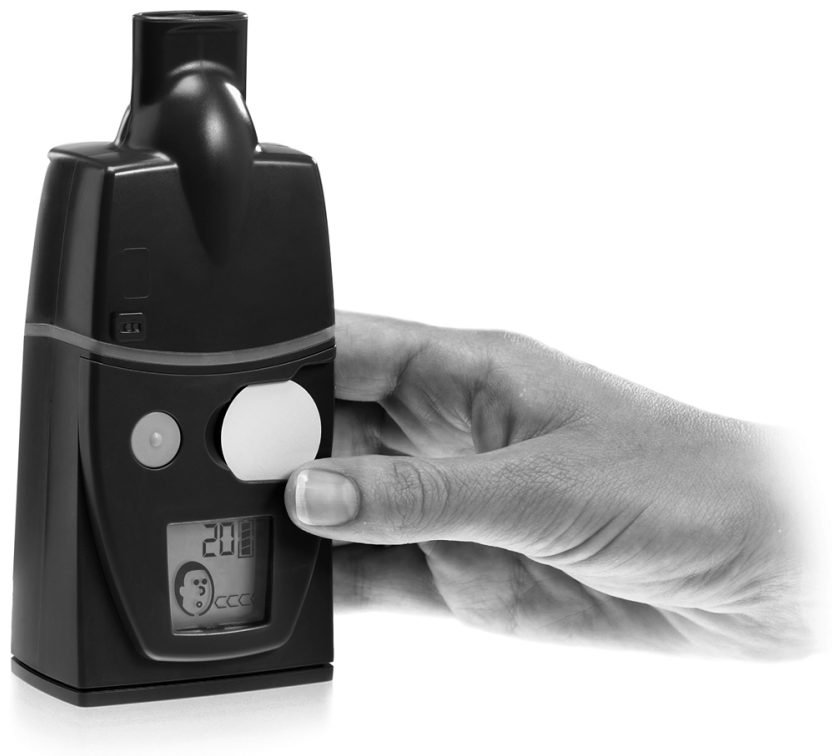

FIG. 1. The I-neb Adaptive Aerosol Delivery (AAD) System.

$300 \mathrm{~mL} / \mathrm{sec}$ ). The I-neb AAD System uses a tactile stimulus to coach the patient to inhale very slowly according to their capability (as long as $9 \mathrm{sec}$ ), and aerosolizes drug during all but the last $2 \mathrm{sec}$, to allow for particle deposition. ${ }^{(9)}$ Figure 2 demonstrates the differences in breathing pattern and timing of aerosol between TBM and TIM (with 6- and 9-sec inhalation times).

The Zemaira formulation has greater purity than the other plasma-derived AAT formulations ${ }^{(2)}$ and is being developed for inhalation. The I-neb AAD System has features that can reduce drug waste, enhance deposition efficiency and reproducibility, and save time. The purpose of this study was to evaluate the aerosol characteristics of AAT delivery by the I-neb AAD System in the TBM and two TIM breathing patterns, and to assess the potential for use in future clinical trials of AAT.

\section{Study Design}

Three new I-neb AAD System devices with $0.5 \mathrm{~mL}$ metering chambers were used for this protocol. The AAD Disc provided a power level of 12. Each device was studied once for each breath-simulation pattern.

Each vial containing $1000 \mathrm{mg}$ lyophilized AAT (Zemaira) was reconstituted with distilled water to a total volume of $20 \mathrm{~mL}$, for a concentration of $50 \mathrm{mg} / \mathrm{mL}$. Each vial also contained $81 \mathrm{mM}$ sodium, $38 \mathrm{mM}$ chloride, $17 \mathrm{mM}$ phosphate, and $144 \mathrm{mM}$ mannitol. Devices were charged with $25 \mathrm{mg}$ AAT using the $0.5 \mathrm{~mL}$ metering chamber for each study.

Patient breathing simulation was accomplished with the PARI COMPAS breath simulator (PARI Aerosol Research Institute, Munich, Germany), programmed for either tidal breathing (TBM), or two different targeted inhalation modes (TIM) using a 6-sec or 9-sec inspiratory time (Table 1). For the TIM breathing pattern studies, devices were operated for a minimum of three complete cycles with the breath simulator prior to the study to "train" the device to achieve the specific breathing pattern. 


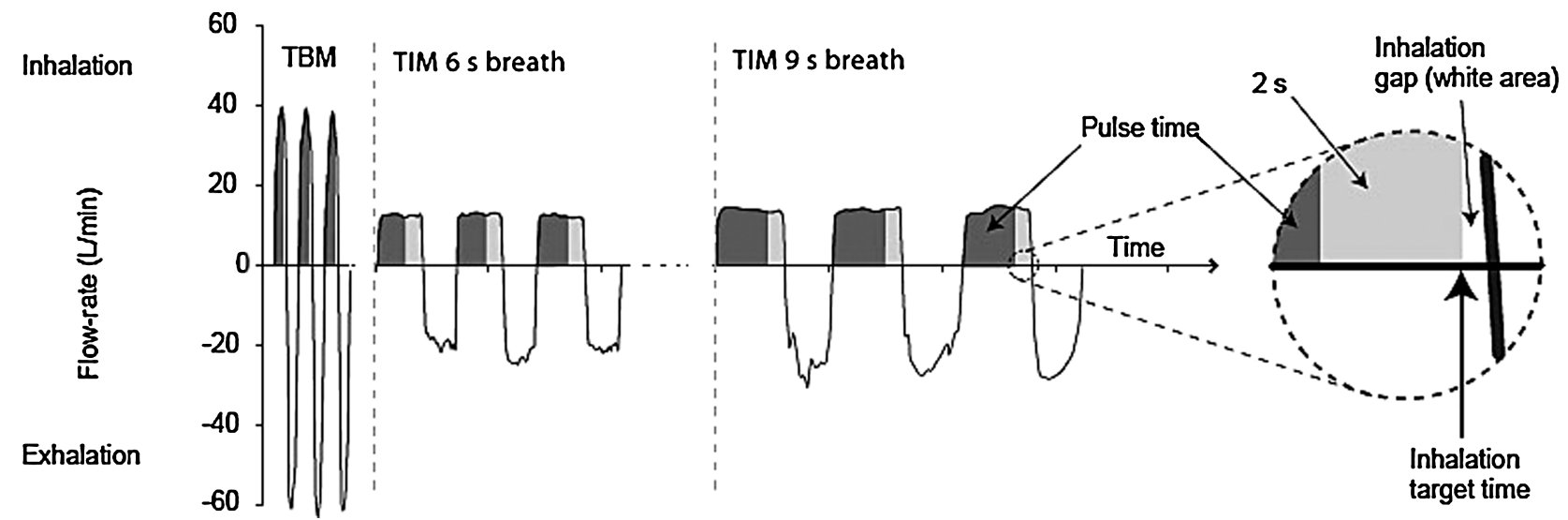

FIG. 2. Breath patterns for Tidal Breathing Mode (TBM) and Targeted Inhalation Mode (TIM) with 6- and 9-sec inspiratory times.

Particle sizing was performed with an Insitec Spraytec laser-diffraction system with closed inhalation cell to measure volume median diameter (VMD) and geometric standard deviation (GSD). The aerosol was drawn through the inhalation cell using the breath simulator, and measurements were obtained during each inspiratory maneuver and averaged.

To measure the emitted ("inhaled") dose, we placed a lowresistance absolute filter (Respirgard bacterial/viral filter, part \#303, Vital Signs, Inc., Totowa, NJ, USA) between the I-neb AAD System and the breath simulator. Drug captured on the inspiratory filter was eluted with distilled water. After generating calibration dilution curves, the samples were analyzed with a spectrophotometer (Genesys 5, Spectronic Instruments, Rochester, NY, USA) and the amount of drug deposited on the filter was calculated.

Predicted lung dose (PLD) was estimated using in vivo data from prior scintigraphy work with the I-neb AAD System in the TBM and TIM modes. ${ }^{(10)}$ In that study of 12 healthy adults, the average whole lung deposition with TBM was $63 \%$ and with TIM was $73 \%$ of the emitted dose. To calculate predicted lung dose we multiplied the amount of drug on the inspiratory filter (emitted dose) by the proportion of deposited dose in that study ( 0.63 for TBM; 0.73 for TIM). We also calculated fine particle dose (i.e., the dose contained in particles $<5 \mu \mathrm{m}$ ) and compared it to predicted lung dose.

\section{Results}

The results for particle sizing and nebulizer performance are summarized in Table 2. Particle size distributions were similar in the different breathing modes, as were fine particle doses. Residual doses were low, between 8 and 13\% of the

TABle 1. PARI COMPAS BREATHING Simulator WITH SETTINGS

\begin{tabular}{lrrrc}
\hline & Resp. rate & Insp. time & Volume & Peak insp. flow \\
\hline TIM-9 & 4bpm & 9 seconds & $1620 \mathrm{~mL}$ & 11 Lpm \\
TIM-6 & 6 bpm & 6 seconds & $1620 \mathrm{~mL}$ & 17 Lpm \\
TBM & 15bpm & 2 seconds & $500 \mathrm{~mL}$ & 25 Lpm \\
\hline
\end{tabular}

loaded metered doses. Emitted doses from the I-neb AAD System were very high, and similar between breathing modes (82-90\% of loaded metered dose).

The published scintigraphy data for the I-neb AAD System in the TBM and TIM modes were used to estimate what the lung dose would be in a person using these breathing patterns. ${ }^{(10)}$ As we suspected, the predicted lung dose (based on scintigraphy) exceeded the fine particle dose (based on simulated breathing) for TIM- 6 and TIM-9, indicating that particles larger than $5 \mu \mathrm{m}$ reach the lung if the inspiration is slow and controlled. For the TBM pattern, the predicted lung dose based on scintigraphy was similar to the fine particle dose.

The duration of nebulization was shortest for TIM-9, intermediate for TIM-6, and longest for TBM. It took only $2.5 \mathrm{~min}$ to nebulize the dose for TIM-9, compared to $7.5 \mathrm{~min}$ with TBM. Therefore, the respirable output reported in PLD/min was the highest with TIM-9.

\section{Discussion}

There are two main aerosol issues regarding the use of inhaled AAT in cystic fibrosis. First, the finite supply of AAT derived from human plasma makes it imperative to use the

Table 2. Aerosol Characteristics of AAT Delivered WITH THE I-neb AAD SYSTEM

\begin{tabular}{lrcc}
\hline & TIM-9 & TIM-6 & TBM \\
\hline VMD ( $\mu \mathrm{m})$ & $4.8 \pm 0.4$ & $4.7 \pm 0.3$ & $4.4 \pm 0.4$ \\
GSD & $1.7 \pm 0.0$ & $1.7 \pm 0.0$ & $1.6 \pm 0.0$ \\
Duration (minutes) & $2.5 \pm 0.1$ & $4.4 \pm 0.3$ & $7.5 \pm 1.3$ \\
Residual dose (mg) & $3.1 \pm 0.3$ & $3.4 \pm 0.6$ & $2.1 \pm 0.3$ \\
Emitted dose (mg) & $22.0 \pm 1.6$ & $20.4 \pm 1.5$ & $22.5 \pm 0.6$ \\
$\begin{array}{l}\text { Predicted lung } \\
\quad \text { dose (PLD, mg) }\end{array}$ & $16.1 \pm 1.0$ & $15.0 \pm 0.9$ & $14.1 \pm 0.3$ \\
$\begin{array}{l}\text { PLD (\% of nominal) } \\
\text { Fine particle }\end{array}$ & $64.5 \%$ & $59.9 \%$ & $56.6 \%$ \\
$\quad \begin{array}{ccc}\text { dose (mg }<\text { microns) } \\
\text { Output (PLD/min) }\end{array}$ & $11.5 \pm 0.7$ & $11.1 \pm 0.7$ & $13.3 \pm 0.3$ \\
\hline
\end{tabular}

Loaded dose was $25 \mathrm{mg}(0.5 \mathrm{~mL})$. Values reported as mean $\pm \mathrm{SD}$. GSD, geometric standard deviation; VMD, volume meter diameter. 
most efficient delivery system to ensure adequate supplies of this scarce resource for patients. Second, the time burden must be minimized for patients who may already be taking multiple other aerosol drugs. Our data show that the I-neb AAD System addresses both of these issues. The residual dose is very small, and the aerosol is generated only during inspiration, minimizing drug waste. The target inhalation mode directs the patient to inhale slowly to avoid particle impaction in the upper airway, allowing more drug to deposit in the lungs. We speculate that the TIM mode may also result in better distribution of drug in the lower airways due to slower particle velocity and less impaction in the proximal airways. ${ }^{(11,12)}$ For patients who are able to use the I-neb AAD System in TIM, delivery time is only one-third that of TBM. Actual in vivo results will vary depending on ability of the subject to inhale slowly and deeply.

It has been previously shown that AAT maintains 93.9\% specific activity after nebulization by the I-neb AAD System. ${ }^{(13)}$ If we assume our estimates of lung dose are correct with the I-neb AAD System, using a loaded dose of $25 \mathrm{mg}$ we expect about 13 to $15 \mathrm{mg}$ of active drug to be deposited in the airways. The few trials of aerosolized AAT in CF suggest that the required dose to neutralize the excess free elastase in $\mathrm{CF}$ sputum are higher, such that initial drug volume and/or concentration may need to be increased for clinical doseramping studies with the I-neb AAD System.

The early studies used the Prolastin formulation of AAT delivered by jet nebulizers. ${ }^{(4,5)}$ The loaded doses ranged from 100 to $350 \mathrm{mg}$ delivered twice daily, with estimates of lung doses between 10 to $70 \mathrm{mg}$ (10-20\% of loaded dose). When the AAT levels in BAL fluid exceeded $8 \mu \mathrm{M}$ after treatment, all free elastase in BAL fluid was inhibited. When sputum levels of free elastase are used instead of BAL fluid levels, the results are not as clear. ${ }^{(2)}$ A pilot study looked at doses of 125, 250, and $500 \mathrm{mg}$ recombinant AAT (PPL Therapeutics, Scotland, UK) delivered by a Pari LC Star ${ }^{\circledR}$ nebulizer (Pari GmbH, Starnberg, Germany) daily for 4 weeks. ${ }^{(14)}$ Sputum myeloperoxidase, a surrogate for neutrophil activity, was reduced only in the high-dose group, whereas there was only an insignificant trend toward reduced sputum free elastase and IL-8 levels. In $\mathrm{CF}$, the neutrophils are concentrated in the airways (sampled by sputum), not the alveoli (sampled by BAL), so it may be more challenging to suppress free elastase in the milieu of the CF airways. Alternatively, the differences may be in the way that samples of BAL and sputum are processed. ${ }^{(2)}$

Breath control devices have been used in other studies with AAT and/or CF subjects. Subsequent to the Brand study on lung deposition versus inhaled breathing pattern, ${ }^{(7)}$ the Akita ${ }^{\circledR}$ system (Inamed GmbH, Gemünden, Germany) was developed and was coupled with commercially available jet nebulizers to control inhalation maneuvers to improve deposition and reduce variability. Based on the patient's lung volume, an individual "smart card" is programmed to determine the inhalation volume, flow, and a breath-holding period, and it also allows for the aerosol to be pulsed during a predetermined portion of the inspiration. ${ }^{(12)}$ In a group of COPD patients, Brand et al. ${ }^{(15)}$ compared delivery of AAT with the Akita coupled with jet nebulizers (inspiratory flow $200 \mathrm{~mL} / \mathrm{sec}$ ) versus spontaneous breathing with the LC Star nebulizer or the HaloLite, a first-generation AAD device. The Akita produced a higher total and higher peripheral lung deposition, reduced variability, and deliv- ered drug two to four times faster than the devices using spontaneous breathing. ${ }^{(15)}$ This finding is remarkably similar to our data from the current study. Another study in $\mathrm{CF}$ patients demonstrated that the Akita with LC Star increased drug delivery (cromolyn sodium) and decreased administration time compared to an LC Star with a manual interrupter, again demonstrating the importance of a controlled, slow inhalation. ${ }^{(16)}$

In an attempt to define the correct airway target for AAT in CF patients, the Akita coupled with jet nebulizers was programmed to deliver $25 \mathrm{mg}$ of AAT to either the lung periphery or the central airways once daily for 4 weeks. ${ }^{(17)}$ The administration time ranged from 5 to $15 \mathrm{~min}$, depending on patient lung function, which also is in line with our I-neb AAD System data (adjusting for the difference in predicted lung dose). Although there was a reduction in free elastase in sputum, neutrophil counts, and pro-inflammatory cytokines, there was no difference in results between the peripheral versus central deposition groups. ${ }^{(17)}$ The results indicate that a higher lung dose will be required to completely neutralize free elastase in CF sputum. Longer term clinical trials are needed to determine whether it is necessary to completely eliminate free-elastase activity, or simply reduce it to see a clinical response.

The Akita paired with a jet nebulizer still has the problem of drug waste in the form of a high residual left in the nebulizer. The Akita2 Apixneb ${ }^{\circledR}$ was developed to solve that problem by coupling Akita technology with a vibrating mesh aerosol generator with a low residual volume. This new system was used in a deposition study for radiolabeled AAT in 20 subjects (healthy, AAT-deficient, or CF). ${ }^{(18)}$ Inspired flow rate was set to $250 \mathrm{~mL} / \mathrm{sec}$, and between 70 and $73 \%$ of the nominal dose was deposited in the lungs, regardless of baseline lung function. The amount of time to deliver approximately $50 \mathrm{mg}$ of AAT to the lung ranged between 5 and 15 min for most subjects. ${ }^{(18)}$ If we extrapolate the I-neb AAD System in TIM-9 data, the estimated time of delivery of $50 \mathrm{mg}$ AAT would be about 8 to 9 minutes, similar to the Akita2 Apixneb study.

The I-neb AAD System and the Akita2 Apixneb both have the capability of delivering large amounts of AAT to the lung in a reasonable time period. They both can control the inhalation pattern and pulse the aerosol in the desired portion of the breath, targeting the lower airways in a precise, reproducible manner. The devices differ in the way they accomplish this goal. The Akita has a compressor that supplies the low airflow and set inspired volume, forcing the patient to breathe in the prescribed manner. The Akita smart card is programmed based on the lung volume of the patient at one point in time. If the patient becomes ill and their lung function declines, the Akita is unable to change unless another smart card is supplied with the new information. On the other hand, the I-neb AAD System uses built-in electronics to continuously monitor the breathing pattern. It coaxes the patient to breathe in a slow, deep fashion through feedback mechanisms, and if the lung function acutely changes, the I-neb AAD System algorithm quickly adjusts to get the best effort possible from the patient at that time. The I-neb AAD System is also battery powered, smaller in size, and portable. These factors and the demonstrated time savings from using the I-neb AAD System with TIM ${ }^{(19)}$ make this device more convenient to use for $\mathrm{CF}$ patients. 


\section{Conclusion}

For effective therapy with inhaled AAT, it is essential to optimize the delivery to the lung by using a slow, controlled inhalation and by minimizing drug waste. The time of administration has to be short to keep the patient burden low. The I-neb AAD System operated in the targeted inhalation mode performed well with regard to these parameters, and is a good delivery-system candidate for clinical trials of AAT.

\section{Acknowledgments}

The authors thank CSL Behring in Kankakee, IL, for funding this project, and for supplying the Zemaira used for the study. We also thank Philips Respironics in Parsippany, NJ, for supplying the I-neb AAD System devices, and in particular, Kurt Nikander for his technical assistance and guidance.

\section{Author Disclosure Statement}

D.E.G. is a consultant to CSL Behring for CF-related issues. His laboratory has received research funding from CSL Behring, PARI, and Philips Respironics.

\section{References}

1. Chmiel JF, Konstan MW: Inflammation and anti-inflammatory therapies for cystic fibrosis. Clin Chest Med. 2007;28:331346.

2. Griese M, Kappler M, Gaggar A, Hartl D: Inhibition of proteases in cystic fibrosis lung disease. Eur Respir J 2008; 32:783-795.

3. Hubbard RC, Crystal RG: Strategies for aerosol therapy of alpha1-antitrypsin deficiency by the aerosol route. Lung Suppl. 1990;168:565-578.

4. McElvaney NG, Hubbard RC, Birrer P, Chernick MS, Caplan DB, Frank MM, Crystal RG: Aerosol $\alpha 1$-anti-trypsin treatment for cystic fibrosis. Lancet 1991;337:392-394.

5. Berger M, Konstan MW, Hilliard JB: Aerosolized prolastin ( $\alpha 1$-protease inhibitor) in CF. Pediatr Pulmonol. 1995;20:421.

6. Sawicki GS, Sellers DE, Robinson WM: High treatment burden in adults with cystic fibrosis: challenges to disease self-management. J Cystic Fibros. 2009;8:91-96.

7. Brand P, Friemel I, Meyer T, Schulz H, Heyder J, Häussinger $\mathrm{K}$ : Total deposition of therapeutic particles during spontaneous and controlled inhalations. J Pharm Sci 2000;89:724-731.

8. Brand P, Meyer T, Häussermann S, Schulte M, Scheuch G, Bernhard T, Sommerauer B, Weber N, Griese M: Optimum peripheral drug deposition in patients with cystic fibrosis. J Aerosol Med 2005;18:45-54.

9. Nikander K, Denyer J: Adaptive aerosol delivery (AAD) technology. In: Rathbone MJ (ed). Modified Release Drug Delivery Technology, 2nd ed. Informa Healthcare USA, Inc., New York, NY; pp. 603-612, 2008.
10. Nikander K, Prince IR, Coughlin SR, Warren S, Taylor G: Mode of breathing - tidal or slow and deep-through the Ineb Adaptive Aerosol Delivery (AAD) system affects lung deposition of $99 \mathrm{mTc}$-DTPA. Proceedings of Drug Delivery to the Lungs, Vol. 17. Edinburgh, Scotland; pp. 206-209, 2006.

11. Laube BL, Jashnani R, Dalby RN, Zeitlin PL: Targeting aerosol deposition in patients with cystic fibrosis. Chest. 2000;118:1069-1076.

12. Bennett WD: Controlled inhalation of aerosolized therapeutics. Expert Opin Drug Deliv. 2005;2:763-767.

13. CSL Behring: Technical Operations memo: effect of nebulization on Zemaira specific activity. CSL Behring, King of Prussia, PA; 2007.

14. Martin SL, Downey D, Bilton D, Keogan MT, Edgar J, Elborn JS: Safety and efficacy of recombinant alpha1-antitrypsin therapy in cystic fibrosis. Pediatr Pulmonol. 2006;41:177183.

15. Brand P, Beckmann H, Enriquez MM, Meyer T, Müllinger B, Sommerer K, Weber N, Weuthen T, Scheuch G: Peripheral deposition of $\alpha 1$-protease inhibitor using commercial inhalation devices. Eur Respir J 2003;22:263-267.

16. Köhler E, Sollich V, Schuster-Wonka R, Jorch G: Lung deposition after electronically breath-controlled inhalation and manually triggered conventional inhalation in cystic fibrosis patients. J Aerosol Med 2005;18:386-395.

17. Griese M, Latzin P, Kappler M, Weckerle K, Heinzlmaier T, Bernhardt T, Hartl D: $\alpha 1$-Antitrypsin inhalation reduces airway inflammation in cystic fibrosis patients. Eur Respir J. 2007;29:240-250.

18. Brand P, Schulte M, Wencker M, Herpich CH, Klein G, Hanna K, Meyer T: Lung deposition of inhaled $\alpha 1$-proteinase inhibitor in CF and $\alpha 1$-antitrypsin deficiency. Eur Respir J 2009;34:354-360.

19. Denyer J, Black A, Nikander K, Dyche T, Prince I: Domiciliary experience of the target inhalation mode (TIM) breathing maneuver in patients with cystic fibrosis. J Aerosol Med Pulm Drug Deliv. 2010;23(Suppl 1):S45-S54.

Received on September 30, 2009 in final form, December 12, 2009

Reviewed by: Beth Laube

Address correspondence to: David E. Geller, M.D. Nemours Children's Clinic Aerosol Research Laboratory 496 S. Delaney Ave, \#406A

Orlando, FL 32801

E-mail: dgeller@nemours.org. 


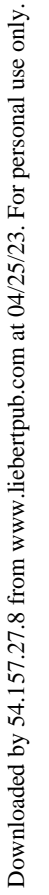

